Check for updates

New York

Cite this as: BMJ 2021;374:n1742 http://dx.doi.org/10.1136/bmj.n1742 Published: 08 July 2021

\title{
Covid-19: Biden renews vaccines push as cases and deaths rise among unvaccinated people
}

\section{Janice Hopkins Tanne}

President Joe Biden has outlined the ways his team is pushing to get more Americans vaccinated, as the highly contagious delta variant spreads and is now causing half of all new SARS-CoV-2 infections in the US.

In a speech on 6 July Biden urged Americans to get vaccinated, calling it a "wartime effort."

"Do it now for yourself and the people you care about, for your neighbourhood, for your country," he said. "It sounds corny, but it's a patriotic thing to do."1

Biden added that vaccination worked and that numbers of covid-19 cases and deaths were down by 90\% from January. He said that millions of fully vaccinated people were getting back to their normal lives and businesses were reopening but added that millions remained unvaccinated and their communities unprotected.

As of 7 July the US had reported 33770334 cases of covid-19 and 606217 deaths, by far the highest numbers of any nation. ${ }^{2}$

The delta variant has been detected in all 50 states and the District of Columbia. Although the US is approaching 160 million people fully vaccinated-more than half the population over age 12-cases are still rising, and the delta variant now causes most new infections, especially in southern and midwestern states that voted for Donald Trump and where vaccination rates are low. Biden said that more than 182 million people in the US had received at least one shot, including $90 \%$ of those over 65 and nearly $70 \%$ of adults over 27 .

States with below-average vaccination rates have almost three times the rate of new cases as states with above-average rates. ${ }^{3}$ Cases were rising in at least 30 of the 50 states. ${ }^{4}$

The proportion of people who have received at least one shot of the vaccine range from a high of $74 \%$ in Vermont to $37 \%$ in Mississippi. ${ }^{5}$

Anthony Fauci, director of the National Institute of Allergy and Infectious Diseases, said that about 99\% of recent covid-19 deaths were among unvaccinated people. He told NBC that it was "sad and tragic that most of these [deaths] are avoidable and preventable." ${ }^{6}$ Maryland governor Larry Hogan, a moderate Republican, said that all covid-19 deaths in his state in the past month were among unvaccinated people. ${ }^{7}$

Biden said he would use a "targeted, community-by-community, door-to-door outreach" campaign to get more Americans vaccinated. His plan emphasised getting the vaccine to primary care doctors and to doctors and other health workers who serve adolescents aged 12 to 18 . Young people can get vaccinated as part of the checkups they need for going back to school or participating in sports in the autumn.

Biden's efforts to reach the unvaccinated include vaccination clinics at workplaces and paid time off to allow workers to get vaccinated. He also said that mobile clinics would be expanded to reach people where they are.

He did not suggest that vaccination became mandatory, although some companies, schools, universities, medical centres, and other institutions are beginning to require vaccinations.

Remarks by President Biden on the covid-19 response and the vaccination program. White House. 6 Jul 2021. https://www.whitehouse.gov/briefing room/speeches-remarks/2021/07/06/remarks-by-president-biden-on-thecovid-19-response-and-the-vaccination-program.

2 Covid-19 Dashboard. Johns Hopkins University. https://www.arcgis.com/apps/dashboards/bda7594740fd40299423467b48e9ecf6.

3 Yan H, Holcombe M. CNN. Rates of new covid-19 cases are almost 3 times higher in states with low vaccination rates, new data shows. CNN. 5 Jul 2021. https://www.cnn.com/2021/07/05/health/us-coronavirus-monday/index.html.

4 Tracking coronavirus and outbreaks in the US. Reuters. 6 Jul 2021. https://graphics.reuters.com/HEALTH-CORONAVIRUS/USATRENDS/dgkvlgkrkpb.

5 See how vaccinations are going in your county and state. New York Times. 7Jul 2021. https://www.nytimes.com/interactive/2020/us/covid-19-vaccinedoses.html.

6 Fauci: $99 \%$ of covid-19 deaths in us are unvaccinated people. Microsoft News. 5 Jul 2021. https://www.msn.com/en-us/news/us/fauci-99percentof-covid-19-deaths-in-us-are-unvaccinated-people/ar-AALLzqr.

7 Hein A. Maryland says 100\% of covid-19 deaths last month were among unvaccinated. Fox News. https://www.foxnews.com/health/maryland-100 percent-june-covid-19-deaths-unvaccinated.

This article is made freely available for use in accordance with BMJ's website terms and conditions for the duration of the covid-19 pandemic or until otherwise determined by BMJ. You may use, download and print the article for any lawful, non-commercial purpose (including text and data mining) provided that all copyright notices and trade marks are retained. 